\title{
The dark side of the spoon - glucose, ketones and COVID-19: a possible role for ketogenic diet?
}

Antonio Paoli ${ }^{1}$, Stefania Gorini ${ }^{2}$ (]) and Massimiliano Caprio ${ }^{2,3^{*}}$ (1)

\begin{abstract}
The novel coronavirus disease (COVID-19) is posing a serious challenge to the health-care systems worldwide, with an enormous impact on health conditions and loss of lives. Notably, obesity and its related comorbidities are strictly related with worse clinical outcomes of COVID-19 disease. Recently, there is a growing interest in the clinical use of ketogenic diets (KDs), particularly in the context of severe obesity with related metabolic complications. KDs have been proven effective for a rapid reduction of fat mass, preserving lean mass and providing an adequate nutritional status. In particular, the physiological increase in plasma levels of ketone bodies exerts important anti-inflammatory and immunomodulating effects, which may reveal as precious tools to prevent infection and potential adverse outcomes of COVID-19 disease. We discuss here the importance of KDs for a rapid reduction of several critical risk factors for COVID-19, such as obesity, type 2 diabetes and hypertension, based on the known effects of ketone bodies on inflammation, immunity, metabolic profile and cardiovascular function. We do believe that a rapid reduction of all modifiable risk factors, especially obesity with its metabolic complications, should be a pillar of public health policies and interventions, in view of future waves of SARS-CoV-2 infection.
\end{abstract}

Keywords: Sars-CoV-2, VLCKD, Obesity, Diabetes, Hyperglycaemia, Inflammation, Metabolic rehabilitation

\section{Introduction}

Data from World Health Organization (WHO) indicate that seasonal influenza causes about 3 to 5 million cases of severe illness, 290,000 to 650,000 deaths from respiratory causes and 99,000-200,000 deaths from lower respiratory tract infections [1]. In general, acute respiratory infections are one of the leading causes of morbidity around the world and, more specifically, lower respiratory tract infections are the leading infectious cause of death and the fifth-leading cause of death overall.

In consideration of the relative low effectiveness of influenza vaccination, public health practices have been

*Correspondence: massimiliano.caprio@sanraffaele.it

${ }^{2}$ Laboratory of Cardiovascular Endocrinology, IRCCS San Raffaele Pisana, Via di Val Cannuta, 247, 00166 Rome, Italy

Full list of author information is available at the end of the article implemented by health authorities in order to limit the spread of respiratory viruses. Common suggested health practices are related to peoples' behaviors as hand washing, use of face masks and eye protection, social distancing, and were encouraged during the pandemic spread of Coronavirus 2019 disease (COVID-19), caused by a virus (SARS-CoV-2) for which there is not yet a vaccine [2], nor effective pharmacological treatments, so far.

\section{Risk factors for COVID-19: role of lifestyle behaviors}

Despite the current mortality rate is $2.3 \%$ [3], the emergence of large number of infected patients within a short period of time determined relevant difficulties in healthcare system of several countries, with an enormous loss of lives. Among risk factors for SARS-CoV-2, numerous studies identified a specific association of COVID-19 
fatality with advanced chronological age [3] and presence of comorbidities, particularly diabetes, hypertension, obesity and chronic kidney disease [4]. Some of these diseases are related to lifestyle behavior, thus it should be mandatory to act on the aforementioned risk factors to improve patients' outcomes and to reduce health's impact of possible future new outbreaks [5].

It is worth to mention that also the increase of sedentarism happened during the recent lockdown measures led to a negative impact on general health condition. The sedentarism due to shelter in place policy enforced in several countries during COVID-19 pandemic, displayed deleterious effects on skeletal muscle metabolism, inducing insulin resistance, fat deposition and low-grade systemic inflammation, with an overall worsening of metabolic parameters, glucose control and inflammatory status. In this regard, sarcopenic obesity, characterized by the coexistence of excessive adiposity and low muscle mass, is strongly associated with increased cardiovascular risk, insulin resistance and low-grade inflammation; therefore, it represents, together with inadequacy of nutritional status, a condition associated with increased susceptibility to viral infection [6]. Importantly, critically ill COVID-19 patients with obesity and malnutrition showed worse outcomes than obese patients without malnutrition [7].

During the lockdown, lifestyle and eating habits of a great part of the worldwide population have dramatically changed. The most important nutritional advice was to reduce the consumption of junk food and to prefer food items with antioxidant and anti-inflammatory properties, with the potential to positively affect the immune system $[8,9]$. It is known that unhealthy nutritional habits, rich in fat and carbohydrates, are associated with obesity and sleep disturbances. Importantly, a marked decrease in sleep quality and an associated increase in body mass index has been described during the quarantine [10]. Moreover, the decreased amount of physical activity during quarantine has affected significantly population's general health $[6,11,12]$. Therefore, there is the real risk that a higher number of patients with obesity and poor blood glucose control will be exposed to novel waves of SarsCov2 infection.

\section{Obesity and hyperglycemia: two villains on COVID-19 stage}

Obesity represents one of the recognized prognostic factor for requirement of intensive care and high risk of death during SARS-CoV-2 infection [13]. In keeping with this, an important shift of severe COVID-19 disease to younger age has been clearly documented with obesity [14]. Obesity affects several critical functions, characterizing an increased vulnerability towards COVID-19 adverse outcomes [15]. Obesity state restricts ventilation by disrupting diaphragm excursion, alters immune responses to viral infection [16], determines a chronic, low-grade inflammation, and worsens glucose tolerance and oxidative stress with adverse effects on cardiovascular function [17]. Importantly, obese patients experience a more severe COVID-19 syndrome, since obesity is characterized by an altered hemostatic balance with increased coagulation and defective fibrinolysis, which results in a pro-thrombotic state [18]. Furthermore, the co-existence of obesity and metabolic-associated fatty liver disease (MAFLD) determines a 6-fold increased risk of severe outcome of COVID-19, independently of age, sex, smoking, diabetes, hypertension and dyslipidemia [19].

Notably, a recent report showed that adipose tissue expresses very high levels of transcripts for ACE2 [20], an enzyme attached to the outer surface of pneumocytes, which is used by coronaviruses to enter and infect cells, raising the question whether adipose tissue may represent a reservoir of SARS-CoV-2, and a strategical site to amplify the cytokines cascade triggered by viral infection [21].

The global epidemic of COVID-19 has also determined important implications on the therapy of common metabolic disorders such as type 2 diabetes (T2D), since two coronavirus receptor proteins, dipeptidyl peptidase-4 (DPP4) and angiotensin-converting enzyme 2 (ACE2) are well established transducers of metabolic signals controlling glucose homeostasis, together with other pathways involved in the regulation of cardiovascular physiology, inflammation and renal activity [22]. Glucose-lowering agents like DPP4 inhibitors, widely used in T2D therapy, can modify the biological activities of multiple immunomodulatory substrates [23]. ACE2 is the entry receptor recognized by the spike (S) protein of SARS-CoV-2, and is known to be expressed in several different tissues including the lung, the kidney tubules, the heart, the luminal surface of the small intestine, adipose tissue and blood vessels [24]. Urinary ACE2 protein concentration and its enzymatic activity are increased in subjects with both type 1 diabetes (T1D) [25] and T2D [26]. Whether hyperglycemia can regulate ACE2 expression in human tissues has not been sufficiently established yet, but it is known that in mouse models of diabetes, ACE2 is overexpressed in the lung, kidney, and heart [27]. In addition, several medications for the treatment of hypertension such as ACE inhibitors (ACEi) and angiotensin receptor blockers (ARBs), are known to upregulate ACE2 expression [28]. Thus, due to increased ACE2 receptor expression in multiple tissues of diabetic patients, it has been argued that the severity of COVID-19 might potentially be exacerbated [29]. Nevertheless, in consideration of the 
well-established organ protective effects of renin angiotensin aldosterone system (RAAS)-inhibitors, several authoritative scientific societies recommended against the discontinuation of these drugs in patients with high risk of COVID-19 infection [30]. However, the possibility to avoid or interrupt potentially harmful pharmacological therapies with a lifestyle intervention should be carefully taken into consideration.

Diabetes is associated with an increased risk of severe viral respiratory tract infections, including H1N1 influenza, given that elevated glucose levels can also suppress anti-viral responses [31]. In China, a study on more than 500 subjects hospitalized with SARS-CoV-2 revealed that high fasting glucose levels determined increased rates of death [32].

Moreover high glucose plasma levels and diabetes were independent predictors of mortality in patients with SARS [33] and during the $2009 \mathrm{H} 1 \mathrm{~N} 1$ pandemic, diabetes was shown to increase the severity of infection [31]. In accordance, influenza and MERS-CoV-infected diabetic mice showed increased illness gravity $[34,35]$.

In a study conducted on 5700 patients affected by COVID-19 and hospitalized in the New York City area, diabetic patients were more likely to have received invasive mechanical ventilation compared with non-diabetic ones [36] suggesting that individuals with diabetes may display impaired alveolar function. Importantly in diabetic animal models structural changes in the lung were observed, such as collapsed alveolar epithelium and elevated vascular permeability [37]. Moreover, endothelial capillary basal lamina and alveolar epithelium are thicker in diabetic patients compared to non-diabetic individuals [38]. Notably, a recent work by Iacobellis and colleagues showed that hyperglycemia at admission was the best predictor of radiographic imaging of acute respiratory distress syndrome (ARDS), independently of the medical history of diabetes. Acute hyperglycemia may lead to an abnormal inflammatory and immune response contributing to the development and progression of the radiographic findings of ARDS in patients with COVID-19 [39]. In addition, structure-function studies suggest that the spike protein of SARS-CoV-2 is highly glycosylated [40] and it has been hypothesized that high concentration of glycosylated SARS-CoV-2 viral particles and glycosylated ACE2 in the lung epithelium, due to hyperglycemia, may influence the susceptibility to COVID-19 infection and its subsequent severity [41]. As a matter of fact, higher glucose plasma levels can increase glucose concentration in airway secretions, and pulmonary epithelial cells exposure to high glucose concentrations is known to enhance influenza virus infection and replication [42, 43]. A recent report provided evidence that elevated glucose levels are strictly involved in viral replication: interestingly, SARS-CoV-2 infection increases mitochondrial ROS production, which induces stabilization of hypoxia-inducible factor- $1 \alpha$ (HIF- $1 \alpha)$. This, in turn, shifts the metabolic features of monocytes/ macrophages into highly glycolytic, leading to an exaggerated SARS-CoV-2 replication rate [44]. In keeping with this, a recent study in vitro showed that pharmacological inhibition of glycolysis reduced SARS-CoV-2 viral replication in a human colon epithelial carcinoma cell line (Caco-2 cells). Therefore, a reduction of aerobic glycolysis could be important as a metabolic therapy aimed at controlling viral replication [45].

For all these reasons, hyperglycemia and high glycemic variability should be adequately prevented in order to improve the outcomes of COVID-19 patients. It is hence clear that well-controlled blood glucose levels will correlate with lower risk of infection and/or better disease resolution. In consideration of potentially adverse effects of commonly used drugs for type 2 diabetes and its comorbidities, a nutritional approach lowering blood glucose concentrations should be considered as a first option, in order to prevent or reduce Sars-Cov-2 infection risk and related complications.

\section{Inflammation: our mutual friend, which may become harmful}

It is well established that the aberrant release of proinflammatory cytokines and chemokines, induced by SARS-CoV-2 infection, is central for the fatal outcomes of COVID-19 syndrome [46]. A severe progression of COVID-19 disease is determined by a tardive interferon gamma response with a prolonged inflammatory state and lower Treg, NK, and both CD4+and CD8+ cells counts $[47,48]$. It is exhaustively documented that hyperglycemia may worsen the inflammatory response. As a matter of fact, NK cells activity is reduced and proinflammatory M1 macrophages are elevated in diabetic patients $[49,50]$. Furthermore, individuals with diabetes display a chronic low-level pro-inflammatory state, with a well-established Th17/Treg and Th1/Th2 imbalance [51]. High glucose levels amplify cytokine production in monocytes through an increase in mitochondrial ROS [44]. It is hence likely that dysregulated immune cell populations and activity observed in diabetic patients represent important risk factors and determine worsening of the inflammatory response during SARS-CoV2 infection.

Obesity and, more in general, excess adipose tissue are characterized by a low-grade chronic inflammation state. Even though the precise obesity-inflammation mechanism is still not well known, some clues indicate as responsible gut-derived molecules, diet-derived metabolites (such as free fatty acids), intrinsic factors related to the enlargement of the adipocytes such as hypoxia, 
mechanotransduction, cells death [52] and altered secretion of adipokines and cytokines. Monocyte/macrophage recruitment, which is functional for the removal of cellular debris due to adipose cell death, amplifies these mechanisms [53]. Chronic low-grade inflammation should be carefully considered in order to understand the risks of obesity and associated diseases, since several key inflammatory markers are strictly linked with an increased risk of adverse outcomes in obesity-associated comorbidities, such as cardiovascular disease and T2D. There is a large body of evidence indicating a positive correlation between C-reactive protein, known as a marker of systemic inflammation, and body composition [54]. Moreover plasminogen-activator inhibitor [55], erythrocyte sedimentation rate [56] and key inflammatory cytokines $[57,58]$, show a similar positive association in obese individuals, further supporting the strict connections between inflammation and obesity [59-61].

\section{Ketogenic diet as lifestyle behavior approach against COVID-19}

Among lifestyle behaviors it is surprising that nutritional advice are still poorly considered in public health discussions about the prevention or reduction of Sars-Cov-2 infection risk and related complications. Thus, a call to action is needed, in order to promote proper nutrition strategies to improve the immune response and the potential clinical outcomes towards COVID-19.

Recently, Soliman et al. proposed a combination of intermittent fasting and supplementation in mediumchain triglycerides as potential prophylactic strategies or adjuvant therapy to tackle SARS-CoV-2 infection, by means of a change in the host metabolic state from a carbohydrate-dependent glycolytic to a fat-dependent ketogenic state, aimed to alter viral replication [62]. Such metabolic shift causes an increased resistance to mitochondrial stress, an improvement in antioxidant defenses, an augmented autophagy and DNA repair, and a decreased insulin secretion [63]. In this context, ketogenic diets represent a nutritional approach with intriguing theoretical bases for improving the immunological response to Sars-CoV-2 infection in high-risk populations [64].

\section{Ketogenic diets}

Ketogenic diets (KDs) are high-fat, low carbohydrate diets and have been primarily used to treat epilepsy in children since the 1920s [65]. Interestingly, their use has been adapted to face different pathologic conditions (severe obesity, metabolic diseases, migraine, cancer, etc.), by changing macronutrients composition and energy content. In this context, the importance of KDs in the treatment of obesity and its associated comorbidities
(T2D, dyslipidemia, insulin resistance, inflammation) has recently emerged [66, 67]. In particular, very low calorie ketogenic diets (VLCKDs), characterized by a marked restriction of carbohydrate intake, usually lower than $30 \mathrm{~g} /$ day, with a relative increase in the proportions of fat and protein and a total daily energy intake $<800 \mathrm{kcal}$, represent a highly effective nutritional strategy in patients who need a rapid weight loss over a short term period, such as individuals with moderate to severe obesity and associated cardiovascular risk factors, leading to a marked improvement in insulin resistance, glucose and blood pressure control $[66,67]$. Weight loss obtained with VLCKD is mostly secondary to fat mass loss, whereas lean mass and adequate nutritional status is preserved [68]. Importantly, KD has been proven to be an effective and rapid treatment for MAFLD, markedly decreasing liver fat content and hepatic insulin resistance only after 6 days of treatment [69]. Indeed, KDs require a strict medical supervision and therapeutic compliance, together with proper micronutrients and vitamins supplementation. For this reason, contraindications to its utilization should be carefully taken into consideration [67].

There is a large body of evidence demonstrating the efficacy of VLCKD in blood glucose control [52]. As a matter of fact, the very low intake in carbohydrates in this nutritional protocol dampens large spikes in blood sugar, thereby improving glycaemic variability. In obese patients with T2D short term exposure to VLCKD determines a marked improvement in $\beta$-cell function, at a higher extent than what could be explained by the weight loss obtained. The drastic reduction in carbohydrate intake is associated with a significant suppression of hepatic glucose production, due to a marked improvement in hepatic insulin sensitivity [70]. An enhanced insulin response has also been described after a short exposure to a VLCKD regimen, with a recovery of insulin response to a hyperglycemic challenge [71]. For all these reasons, VLCKD could be part of a multidisciplinary strategy for metabolic rehabilitation in patients with diabesity.

KDs exert most of their therapeutic effects by increasing plasma levels of ketone bodies [AcetoAcetate and Beta-hydroxybutyrate $(ß \mathrm{OHB})]$ and decreasing blood glucose. In humans, basal plasma levels of $ß \mathrm{OHB}$ are in the low micromolar range, and reach stable levels around $1 \mathrm{mM}$ during a KD. Beyond its role as energy fuel, $\mathrm{BOHB}$ exerts pleiotropic and heterogeneous effects in cellular physiology, inducing the expression of genes that curtail oxidative stress and displaying remarkable immunomodulating, anti-catabolic [72] and anti-inflammatory [73] effects by different mechanisms in multiple tissues, as recently discussed in an exhaustive review article by Stubbs et al. [74]. Moreover, the well-known blood 
glucose lowering effect of KDs may help to contrast virus infection [44]. Finally, VLCKD has been found effective in blood pressure lowering, due to the increased natriuresis which is associated with ketone bodies urinary excretion [75]. In consideration of the reduced amount of physical activity caused by quarantine and the general changes of daily habits in the populations, physical exercise seems to be a potentiation factor of the aforementioned favorable effects of KDs, such as the improvement of glycaemic control [76], body composition [77], liver fat content [78], and in general metabolic health [79].

\section{Potential preventive effects of ketogenic diet on SARS-CoV-2 infection}

Ketogenic diet may play a role modulating both innate and adaptive immune cells, which synergistically protect the host against pathogens' assaults.

\section{Innate cell-mediated immunity}

Innate immune cells are firstly triggered by viral antigens through the activation of pattern recognition receptors (PRRs), in order to inhibit viral replication and modulate the adaptive immunity [80]. In this context, the NLRP3/ inflammasome is an important innate immunity sensor, mediating virus-induced inflammation through the induction of Interleukine-1 $\beta$ (IL-1 $\beta$ ) and Interleukine-18 (IL-18) secretion [81]. The pattern recognition receptor NLRP3 is a nucleotide oligomerization domain (Nod)like receptor (NLR) that recognizes both damage-associated molecular patterns (DAMPs), such as toxins, ATP, excess of glucose, cholesterol crystals, and pathogenassociated molecular patterns (PAMPs), such as viral and bacterial molecules. For instance, RNA viruses can activate NLRP3 through mitochondrial antiviral signalling protein (MAVS) on the mitochondrial outer membrane. Activated NLRP3 promotes the formation of the inflammasome complex interacting with the adaptor protein ASC (apoptosis-associated speck-like protein containing C-terminal caspase recruitment domain [CARD]), which, in turn, triggers the activation of the zymogen procaspase- 1 into caspase- 1 . Finally, the inflammatory caspase- 1 converts the inactive pro-Interleukine- $1 \beta$ (proIL-1 $\beta$ ) and pro-Interleukine-18 (pro-IL-18) into their corresponding active proinflammatory cytokines [82] (Fig. 1).

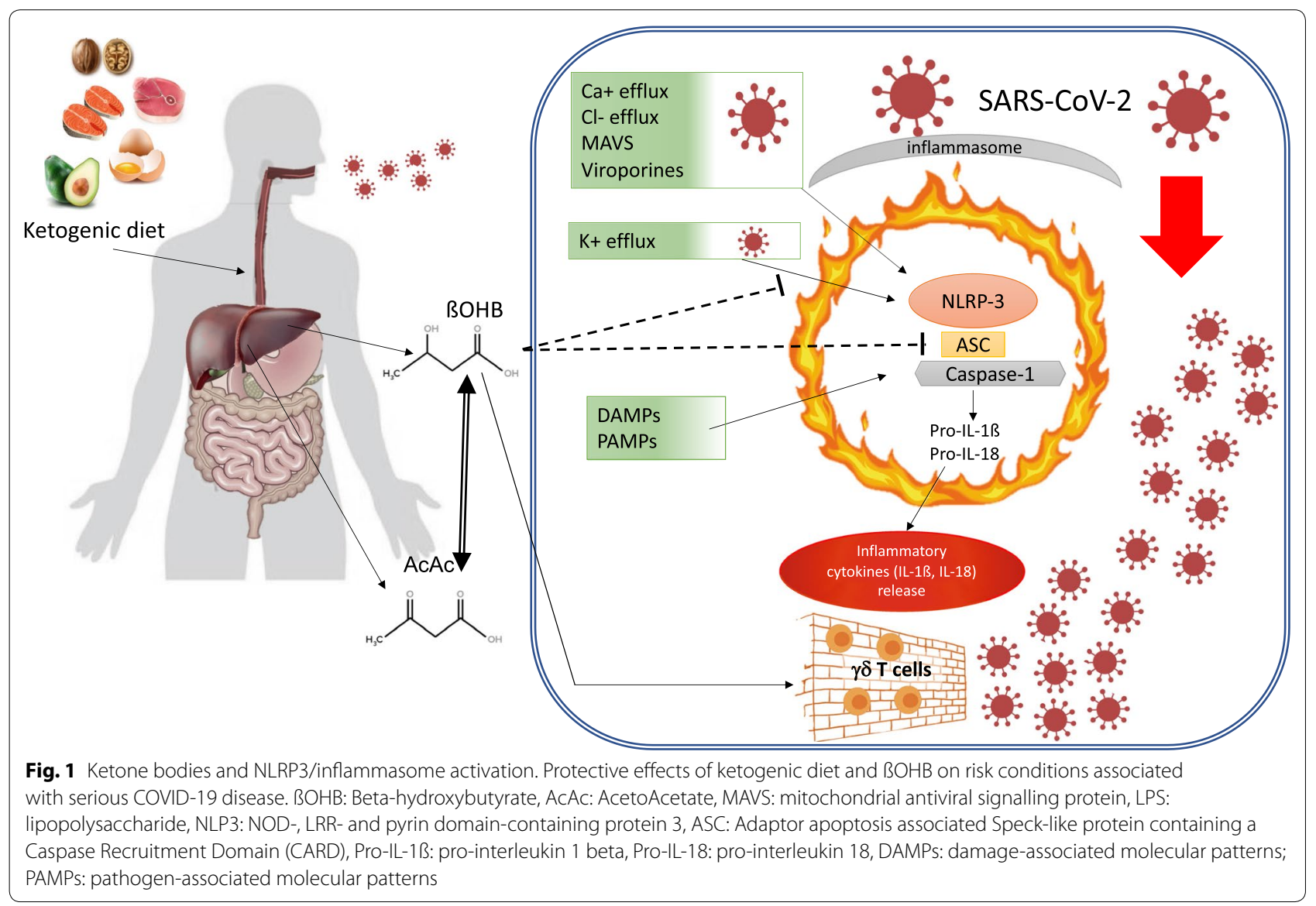


The NLRP3/inflammasome activation due to a viral infection has been documented for influenza A virus (IAV), encephalomyocarditis virus (EMCV), hepatitis $\mathrm{C}$ virus (HCV), and SARS-CoV, and seems to be mediated also by viral proteins known as viroporins, specific molecules [83] which assemble into homo-oligomers and form hydrophilic pores across the cytosolic organelle membranes, thereby increasing $\mathrm{Na}+, \mathrm{K}+$, and $\mathrm{Ca} 2+$ flux. Increased intracellular $\mathrm{Ca} 2+$ concentration and reduced intracellular $\mathrm{K}+$ levels represent important triggering signals for NLRP3/inflammasome activation and the subsequent massive secretion of proinflammatory cytokines [84]. All coronaviruses known so far, including the new spread SARS-CoV2, are able to encode for viroporines $\mathrm{E}$ and $3 \mathrm{a}$ and their expression is functional to the activation of NLRP3/inflammasome in COVID-19 disease [83].

There is growing evidence that $\mathrm{BOHB}$ inhibits NLRP3/ inflammasome activation. The favorable effects of KD on inflammatory cytokines in humans [85], in animal and cellular models [86] are well established. ßOHB is able to act on a central common signaling pathway, specific to the NLRP3/inflammasome, in response to many different pro-inflammatory stimuli. More specifically, $\mathrm{BOHB}$ inhibits NLRP3/inflammasome activation through the reduction of $\mathrm{K}+$ efflux from macrophages and the inhibition of the inflammasome assembly (Fig. 1). Consistent with these observations, ßOHB-dependent inhibition of IL- $1 \beta$ and IL-18 secretion in human monocytes has been documented [73].

In consideration of the role of inflammasome activation in triggering the systemic inflammatory cascade observed in COVID-19 patients [46], approaches based on increasing plasma $ß \mathrm{OHB}$, such as KDs, should be taken into account to prevent the development or the progression of the cytokine storm syndrome.

Interestingly, a recent hypothesis paper underlined the importance of a drastic reduction of glucose oral supply, in order to reduce macrophage M1 polarization in the early stages of inflammation [64]. In fact, the M1 phenotype, whose activation is linked to the cytokine storm syndrome [87], is strictly dependent upon aerobic glycolysis, which is known to be reduced by a drastic reduction in glucose uptake, as it occurs during a KD. On the other hand, KDs could sustain the metabolism of anti-inflammatory M2 macrophages, which abundantly express OXPHOS enzymes through the continuous supply of free fatty acids [64].

\section{Adaptive cell-mediated immunity}

$T$ lymphocytes recognize specific ligands by Tcell receptors (TCR), which are specialized in antigen recognition. In most species, the vast majority of T cells TCR is composed by an $\alpha$ and a $\beta$ chain, and a minor Tcell population expresses a TCR characterized by $\gamma$ and $\delta$ chains. In humans and mice most of $\mathrm{T}$ cells $(>90 \%)$ in peripheral blood and lymphoid organs express the TCR $\alpha / \beta$ chain and only a minority of $\mathrm{T}$ cells $(<10 \%)$ express the TCR $\gamma / \delta$. Interestingly, in mice, $\gamma \delta \mathrm{T}$ cells are the most abundant Tcell population in epithelia and mucosa [88]. The epithelial layers display a peculiar immune system and resident $\mathrm{T}$ lymphocytes, which are in close contact with the epithelial cells. In humans, $\gamma \delta \mathrm{T}$ cells are enriched in skin and mucosa, suggesting a specific function for $\gamma \delta$ $\mathrm{T}$ cells in mucosa layers [88]. Therefore, these cells may play an important role in viral infection surveillance and response in mucosal inner layers of the respiratory trait.

A recent study by Goldberg et al. showed that immunocompetent mice exposed to intranasal challenge of influenza A virus (IAV), displayed better survival when their $\gamma \delta \mathrm{T}$ cell population were increased in the lung, determining an improvement of barrier function and anti-viral response [89]. More specifically, mice underwent $\gamma \delta \mathrm{T}$ cell expansion by means of a ketogenic diet for 7 days, and displayed a better blood $\mathrm{O}_{2}$ saturation compared to control chow-fed mice, with an increased secretory function, mucus production in the airways, and IL-17 production, thereby mediating anti-viral defense and tissue repair through regulatory $\mathrm{T}$ cells (Treg) activation, a cell population which is known to be reduced during the COVID-19 cytokine storm [47].

Notably, $\gamma \delta$ T cells expansion was specifically promoted by $\mathrm{KD}$, since pharmacological increase of $ß \mathrm{OHB}$ failed to induce this phenotype [89], and only endogenous ketone bodies-not the exogenous ketone precursor 1,3-butanediol-were able to protect mice against influenza infection. Importantly, $\gamma \delta \mathrm{T}$ cells can expand in response to IAV and kill IAV-infected airway cells also in humans [90]. Therefore, KD could represent a valuable option in order to physiologically increase $ß O H B$ levels, and optimize adaptive immune cells to prevent Sars-Cov2 infection.

A recent observation showed that $\gamma \delta \mathrm{T}$ cells are also expressed in adipose tissue [91], where they increase IL-17 production, thereby promoting the expansion of Treg cells function, with immuno-modulatory and antiinflammatory properties.

It is therefore tempting to speculate a key role for $\gamma \delta$ $\mathrm{T}$ cells in maintaining barrier integrity against Sars-Cov2 infection in the lung, as well as in adipose tissue, where meta-inflammation could enhance the cytokine reaction in response to viral infection. KD may represent a valid approach to specifically sustain these protective mechanisms (Fig. 1). 


\section{Conclusions}

There are multiple mechanisms through which ketone bodies might impact severe viral infections such as COVID-19 disease. A recent review article exhaustively summarizes this concept, proposing the administration of exogenous ketones to critical patients in order to target respiratory viruses complications as a possible therapy [74].

We believe that KD-induced increase in endogenous ketone bodies could represent a more valuable strategy to prevent Sars-Cov2 infection and adverse outcomes in obese patients, particularly in the current context of a prolonged pandemic emergency. Indeed, prevention and/or correction of all risk conditions associated with serious COVID-19 disease (obesity, hyperglycemia, high glycemic variability, insulin resistance, hypertension) is mandatory, in consideration of new waves of infections, in the absence of effective pharmacological therapies and vaccination. This could be obtained with a nutritional strategy aimed to induce fat mass loss, to reduce chronic inflammation, hepatic and systemic insulin resistance, and to improve nutritional status, cardiovascular health, immune response, glucose homeostasis and blood pressure control.

Finally, the adoption of a well-structured and personalized KD regimen could help a progressive nutritional education and rehabilitation in obese patients, providing an effective tool to modify lifestyle behavior, supporting a long-term control of body weight, and favoring a reduction in all associated risk factors for potentially severe complications related to Sars-Cov2 infection. Welldesigned multicentric studies on the actual incidence of severe COVID-19 disease among obese patients who followed or not a structured protocol of KD, could be helpful to confirm such hypothesis.

During this difficult pandemic era, the adoption of lifestyle preventive measures is mandatory, and should be carefully implemented.

\section{Acknowledgements}

This manuscript is dedicated to the shining memory of Véronique Jeuffroy, her elegance, her strength and courage, her love for life.

\section{Authors'contributions}

AP and MC conceived the review and prepared the first draft of the review. SG wrote part of the manuscript and contributed to the revision. All authors read and approved the final manuscript.

\section{Fundings}

This study was supported by the Italian Ministry of Health (Ricerca Corrente) and by MIUR (Progetti di Ricerca di Interesse Nazionale 2017-project code 2017A5TXC3-to MC, Work Package Leader).

\section{Availability of data and materials}

Not applicable

Ethics approval and consent to participate

Not applicable.
Consent for publication

Not applicable.

\section{Competing interests}

The authors declare that they have no competing interests.

\section{Author details}

${ }^{1}$ Department of Biomedical Sciences, University of Padua, Padua, Italy. ${ }^{2}$ Laboratory of Cardiovascular Endocrinology, IRCCS San Raffaele Pisana, Via di Val Cannuta, 247, 00166 Rome, Italy. ${ }^{3}$ Department of Human Sciences and Promotion of the Quality of Life, San Raffaele Roma Open University, Via di Val Cannuta, 247, 00166 Rome, Italy.

Received: 5 September 2020 Accepted: 30 October 2020

Published online: 20 November 2020

\section{References}

1. WHO. Influenza (seasonal) 2020. https://www.who.int/news-room/factsheets/detail/influenza-(seasonal).

2. WHO. Protecting yourself and others from the spread COVID-19 2020. https://www.who.int/emergencies/diseases/novel-coronavirus-2019/ advice-for-public.

3. Wu Z, McGoogan JM. Characteristics of and important lessons from the Coronavirus Disease 2019 (COVID-19) outbreak in China: summary of a report of 72314 cases from the Chinese Center for Disease Control and Prevention. JAMA. 2020;323(13):1239-42.

4. South AM, Diz DI, Chappell MC. COVID-19, ACE2, and the cardiovascular consequences. Am J Physiol Heart Circ Physiol. 2020;318(5):H1084-90.

5. WHO. Statement-Preparing for the autumn is a priority now at the WHO Regional Office for Europe 2020. https://www.euro.who.int/en/ health-topics/health-emergencies/coronavirus-covid-19/statements/ statement-preparing-for-the-autumn-is-a-priority-now-at-the-who-regio nal-office-for-europe.

6. Narici M, De Vito G, Franchi M, Paoli A, Moro T, Marcolin G, et al. Impact of sedentarism due to the COVID-19 home confinement on neuromuscular, cardiovascular and metabolic health: physiological and pathophysiological implications and recommendations for physical and nutritional countermeasures. Eur J Sport Sci. 2020. https://doi.org/10.1080/17461 391.2020.1761076.

7. Briguglio M, Pregliasco FE, Lombardi G, Perazzo P, Banfi G. The malnutritional status of the host as a virulence factor for new Coronavirus SARSCoV-2. Front Med. 2020;7:146.

8. Muscogiuri G, Barrea L, Savastano S, Colao A. Nutritional recommendations for CoVID-19 quarantine. Eur J Clin Nutr. 2020;74(6):850-1.

9. Barrea L, Muscogiuri G, Frias-Toral E, Laudisio D, Pugliese G, Castellucci $B$, et al. Nutrition and immune system: from the Mediterranean diet to dietary supplementary through the microbiota. Crit Rev Food Sci Nutr. 2020. https://doi.org/10.1080/10408398.2020.1792826.

10. Barrea L, Pugliese G, Framondi L, Di Matteo R, Laudisio D, Savastano S, et al. Does Sars-Cov-2 threaten our dreams? Effect of quarantine on sleep quality and Body Mass Index. J Transl Med. 2020;18(1):318.

11. Mattioli AV, Sciomer S, Cocchi C, Maffei S, Gallina S. Quarantine during COVID-19 outbreak: changes in diet and physical activity increase the risk of cardiovascular disease. Nutr Metab Cardiovasc Dis. 2020;30(9):1409-17.

12. Rehman H, Ahmad MI. COVID-19: quarantine, isolation, and lifestyle diseases. Arch Physiol Biochem. 2020. https://doi.org/10.1080/13813 455.2020.1833346.

13. Kalligeros M, Shehadeh F, Mylona EK, Benitez G, Beckwith CG, Chan PA, et al. Association of Obesity with Disease Severity among Patients with COVID-19. Obesity (Silver Spring). 2020;28(7):1200-4.

14. Kass DA, Duggal P, Cingolani O. Obesity could shift severe COVID-19 disease to younger ages. Lancet. 2020;395(10236):1544-5.

15. Muscogiuri G, Pugliese G, Barrea L, Savastano S, Colao A. Obesity: the "Achilles heel" for COVID-19? Metabolism. 2020;108:154251.

16. Paich HA, Sheridan PA, Handy J, Karlsson EA, Schultz-Cherry S, Hudgens $M G$, et al. Overweight and obese adult humans have a defective cellular immune response to pandemic H1N1 influenza A virus. Obesity. 2013;21(11):2377-86. 
17. GBD Obesity Collaborators. Health effects of overweight and obesity in 195 countries over 25 years. N Engl J Med. 2017;377(1):13-27.

18. Bladbjerg EM, Stolberg CR, Juhl CB. Effects of obesity surgery on blood coagulation and fibrinolysis: a literature review. Thromb Haemost. 2020;120(4):579-91.

19. Zhou YJ, Zheng KI, Wang XB, Yan HD, Sun QF, Pan KH, et al. Younger patients with MAFLD are at increased risk of severe COVID-19 illness: a multicenter preliminary analysis. J Hepatol. 2020;73(3):719-21.

20. Li MY, Li L, Zhang Y, Wang XS. Expression of the SARS-CoV-2 cell receptor gene ACE2 in a wide variety of human tissues. Infect Dis Poverty. 2020;9(1):45.

21. Kassir R. Risk of COVID-19 for patients with obesity. Obes Rev. 2020;21(6):e13034.

22. Mulvihill EE, Varin EM, Gladanac B, Campbell JE, Ussher JR, Baggio LL, et al. Cellular sites and mechanisms linking reduction of dipeptidyl peptidase-4 activity to control of incretin hormone action and glucose homeostasis. Cell Metab. 2017;25(1):152-65.

23. Mulvihill EE, Drucker DJ. Pharmacology, physiology, and mechanisms of action of dipeptidyl peptidase-4 inhibitors. Endocr Rev. 2014;35(6):992-1019.

24. Monteil V, Kwon H, Prado P, Hagelkrüys A, Wimmer RA, Stahl M, et al. Inhibition of SARS-CoV-2 infections in engineered human tissues using clinical-grade soluble human ACE2. Cell. 2020;181(4):905-13.

25. Burns KD, Lytvyn Y, Mahmud FH, Daneman D, Deda L, Dunger DB, et al. The relationship between urinary renin-angiotensin system markers, renal function, and blood pressure in adolescents with type 1 diabetes. Am J Physiol Renal Physiol. 2017;312(2):F335-42.

26. Gutta S, Grobe N, Kumbaji M, Osman H, Saklayen M, Li G, et al. Increased urinary angiotensin converting enzyme 2 and neprilysin in patients with type 2 diabetes. American Journal of Physiology-Renal Physiology. 2018:315(2):F263-74.

27. Roca-Ho H, Riera M, Palau V, Pascual J, Soler MJ. Characterization of ACE and ACE2 expression within different organs of the NOD mouse. Int J Mol Sci. 2017;18(3):563.

28. Drucker DJ. Coronavirus infections and type 2 diabetes — shared pathways with therapeutic implications. Endocr Rev. 2020;41(3):bnaa011.

29. Angelidi AM, Belanger MJ, Mantzoros CS. Commentary: COVID-19 and diabetes mellitus: What we know, how our patients should be treated now, and what should happen next. Metabolism. 2020;107:154245.

30. Position statement of the ESC council on hypertension on ACE-inhibitors and angiotensin receptor blockers [press release]. 2020.

31. Allard R, Leclerc P, Tremblay C, Tannenbaum T-N. Diabetes and the severity of pandemic influenza A (H1N1) infection. Diabetes Care. 2010;33(7):1491-3.

32. Yang J-K, Lin S-S, Ji X-J, Guo L-M. Binding of SARS coronavirus to its receptor damages islets and causes acute diabetes. Acta Diabetol. 2010;47(3):193-9.

33. Yang J, Feng Y, Yuan M, Yuan S, Fu H, Wu B, et al. Plasma glucose levels and diabetes are independent predictors for mortality and morbidity in patients with SARS. Diabet Med. 2006;23(6):623-8.

34. Kulcsar KA, Coleman CM, Beck SE, Frieman MB. Comorbid diabetes results in immune dysregulation and enhanced disease severity following MERSCoV infection. JCl insight. 2019:4(20):e131774.

35. Marshall RJ, Armart P, Hulme KD, Chew KY, Brown AC, Hansbro PM, et al. Glycemic variability in diabetes increases the severity of influenza. Mbio. 2020;11(2):e02841.

36. Richardson S, Hirsch JS, Narasimhan M, Crawford JM, McGinn T, Davidson $\mathrm{KW}$, et al. Presenting characteristics, comorbidities, and outcomes among 5700 patients hospitalized with COVID-19 in the New York City area. JAMA. 2020;323(20):2052-9.

37. Popov D, Simionescu M. Alterations of lung structure in experimental diabetes, and diabetes associated with hyperlipidaemia in hamsters. Eur Respir J. 1997;10(8):1850-8.

38. Weynand B, Jonckheere A, Frans A, Rahier J. Diabetes mellitus induces a thickening of the pulmonary basal lamina. Respiration. 1999;66(1):14-9.

39. lacobellis $G$, Penaherrera CA, Bermudez LE, Mizrachi EB. Admission hyperglycemia and radiological findings of SARS-COv2 in patients with and without diabetes. Diabetes Res Clin Pract. 2020;164:108185.

40. Walls AC, Park Y-J, Tortorici MA, Wall A, McGuire AT, Veesler D. Structure, function, and antigenicity of the SARS-CoV-2 spike glycoprotein. Cell. 2020;181(2):281-92.
41. Brufsky A. Hyperglycemia, hydroxychloroquine, and the COVID-19 pandemic. J Med Virol. 2020;92(7):770-5.

42. Kohio HP, Adamson AL. Glycolytic control of vacuolar-type ATPase activity: a mechanism to regulate influenza viral infection. Virology. 2013:444(1-2):301-9.

43. Philips BJ, Meguer J-X, Redman J, Baker EH. Factors determining the appearance of glucose in upper and lower respiratory tract secretions. Intensive Care Med. 2003;29(12):2204-10.

44. Codo AC, Davanzo GG, de Brito Monteiro L, Fabiano de Souza G, Muraro SP, Virgilio-da-Silva JV, et al. Title: elevated glucose levels favor SARS-CoV-2 infection and monocyte response through a HIF-a/glycolysis dependent axis. Cell Metab. 2020;32:498-9.

45. Bojkova D, Klann K, Koch B, Widera M, Krause D, Ciesek S, et al. Proteomics of SARS-CoV-2-infected host cells reveals therapy targets. Nature. 2020;583(7816):469-72.

46. Mehta P, McAuley DF, Brown M, Sanchez E, Tattersall RS, Manson JJ, et al. COVID-19: consider cytokine storm syndromes and immunosuppression. Lancet. 2020;395(10229):1033-4.

47. Moore JB, June CH. Cytokine release syndrome in severe COVID-19. Science. 2020;368(6490):473-4

48. Wang F, Nie J, Wang H, Zhao Q, Xiong Y, Deng L, et al. Characteristics of peripheral lymphocyte subset alteration in COVID-19 pneumonia. J Infect Dis. 2020;221(11):1762-9.

49. Kim JH, Park K, Lee SB, Kang S, Park JS, Ahn CW, et al. Relationship between natural killer cell activity and glucose control in patients with type 2 diabetes and prediabetes. J Diabetes Investig. 2019;10(5):1223-8.

50. Kratz M, Coats BR, Hisert KB, Hagman D, Mutskov V, Peris E, et al. Metabolic dysfunction drives a mechanistically distinct proinflammatory phenotype in adipose tissue macrophages. Cell Metab. 2014;20(4):614-25.

51. Wang M, Chen F, Wang J, Zeng Z, Yang Q, Shao S. Th17 and Treg lymphocytes in obesity and Type 2 diabetic patients. Clin Immunol. 2018;197:77-85.

52. Reilly SM, Saltiel AR. Adapting to obesity with adipose tissue inflammation. Nat Rev Endocrinol. 2017;13(11):633-43.

53. Nishimura S, Manabe I, Nagasaki M, Eto K, Yamashita H, Ohsugi M, et al. CD8 + effector $T$ cells contribute to macrophage recruitment and adipose tissue inflammation in obesity. Nat Med. 2009;15(8):914-20.

54. Choi J, Joseph L, Pilote L. Obesity and C-reactive protein in various populations: a systematic review and meta-analysis. Obes Rev. 2013;14(3):232-44.

55. Mavri A, Alessi M, Bastelica D, Geel-Georgelin O, Fina F, Sentocnik J, et al. Subcutaneous abdominal, but not femoral fat expression of plasminogen activator inhibitor-1 (PAI-1) is related to plasma PAI-1 levels and insulin resistance and decreases after weight loss. Diabetologia. 2001:44(11):2025-31.

56. De Rooij SR, Nijpels G, Nilsson PM, Nolan JJ, Gabriel R, Bobbioni-Harsch E, et al. Low-grade chronic inflammation in the relationship between insulin sensitivity and cardiovascular disease (RISC) population: associations with insulin resistance and cardiometabolic risk profile. Diabetes Care. 2009;32(7):1295-301.

57. Bahceci M, Gokalp D, Bahceci S, Tuzcu A, Atmaca S, Arikan S. The correlation between adiposity and adiponectin, tumor necrosis factor $\mathrm{a}$, interleukin-6 and high sensitivity C-reactive protein levels. Is adipocyte size associated with inflammation in adults? J Endocrinol Invest. 2007:30(3):210-4.

58. Marques-Vidal P, Bochud M, Bastardot F, Lüscher T, Ferrero F, Gaspoz J-M, et al. Association between inflammatory and obesity markers in a Swiss population-based sample (CoLaus Study). Obes Facts. 2012;5(5):734-44.

59. Collaboration ERF. C-reactive protein, fibrinogen, and cardiovascular disease prediction. N Engl J Med. 2012;367(14):1310-20.

60. Schnabel RB, Yin X, Larson MG, Yamamoto JF, Fontes JD, Kathiresan S, et al. Multiple inflammatory biomarkers in relation to cardiovascular events and mortality in the community. Arterioscler Thromb Vasc Biol. 2013;33(7):1728-33.

61. Spranger J, Kroke A, Möhlig M, Hoffmann K, Bergmann MM, Ristow M, et al. Inflammatory cytokines and the risk to develop type 2 diabetes: results of the prospective population-based European Prospective Investigation into Cancer and Nutrition (EPIC)-Potsdam Study. Diabetes. 2003;52(3):812-7. 
62. Soliman S, Faris ME, Ratemi Z, Halwani R. Switching host metabolism as an approach to dampen SARS-CoV-2 infection. Ann Nutr Metab. 2020. https://doi.org/10.1159/000510508.

63. de Cabo R, Mattson MP. Effects of intermittent fasting on health, aging, and disease. N Engl J Med. 2019;381(26):2541-51.

64. Sukkar SG. Bassetti M Induction of ketosis as a potential therapeutic option to limit hyperglycemia and prevent cytokine storm in COVID-19. Nutrition. 2020. https://doi.org/10.1016/j.nut.2020.110967.

65. Wilder RM. The effects of ketonemia on the course of epilepsy. Mayo Clin Proc. 1921;2:307-8.

66. Paoli A, Rubini A, Volek JS, Grimaldi KA. Beyond weight loss: a review of the therapeutic uses of very-low-carbohydrate (ketogenic) diets. Eur J Clin Nutr. 2013;67(8):789-96.

67. Caprio M, Infante M, Moriconi E, Armani A, Fabbri A, Mantovani G, et al. Very-low-calorie ketogenic diet (VLCKD) in the management of metabolic diseases: systematic review and consensus statement from the Italian Society of Endocrinology (SIE). J Endocrinol Invest. 2019;42(11):1365-86.

68. Gomez-Arbelaez D, Crujeiras AB, Castro Al, Martinez-Olmos MA, Canton A, Ordoñez-Mayan L, et al. Resting metabolic rate of obese patients under very low calorie ketogenic diet. Nutr Metab. 2018;15(1):18.

69. Luukkonen PK, Dufour S, Lyu K, Zhang XM, Hakkarainen A, Lehtimaki TE, et al. Effect of a ketogenic diet on hepatic steatosis and hepatic mitochondrial metabolism in nonalcoholic fatty liver disease. Proc Natl Acad Sci USA. 2020;117(13):7347-54.

70. Lim EL, Hollingsworth KG, Aribisala BS, Chen MJ, Mathers JC, Taylor R. Reversal of type 2 diabetes: normalisation of beta cell function in association with decreased pancreas and liver triacylglycerol. Diabetologia. 2011:54(10):2506-14

71. Malandrucco I, Pasqualetti P, Giordani I, Manfellotto D, De Marco F, Alegiani F, et al. Very-low-calorie diet: a quick therapeutic tool to improve beta cell function in morbidly obese patients with type 2 diabetes. Am J Clin Nutr. 2012;95(3):609-13.

72. Puchalska P, Crawford PA. Multi-dimensional roles of ketone bodies in fuel metabolism, signaling, and therapeutics. Cell Metab. 2017;25(2):262-84.

73. Youm YH, Nguyen KY, Grant RW, Goldberg EL, Bodogai M, Kim D, et al. The ketone metabolite beta-hydroxybutyrate blocks NLRP3 inflammasomemediated inflammatory disease. Nat Med. 2015;21(3):263-9.

74. Stubbs BJ, Koutnik AP, Goldberg EL, Upadhyay V, Turnbaugh PJ, Verdin E, et al. Investigating ketone bodies as immunometabolic countermeasures against respiratory viral infections. Med. 2020. https://doi.org/10.1016/j. medj.2020.06.008

75. Kolanowski J, Bodson A, Desmecht P, Bemelmans S, Stein F, Crabbe J. On the relationship between ketonuria and natriuresis during fasting and upon refeeding in obese patients. Eur J Clin Invest. 1978;8(5):277-82.

76. Michalczyk MM, Klonek G, Maszczyk A, Zajac A. The effects of a low calorie ketogenic diet on glycaemic control variables in hyperinsulinemic overweight/obese females. Nutrients. 2020;12(6):1854.

77. Michalczyk M, Zajac A, Mikolajec K, Zydek G, Langfort J. No modification in blood lipoprotein concentration but changes in body composition after 4 weeks of low carbohydrate diet (LCD) followed by 7 days of carbohydrate loading in basketball players. J Human Kinet. 2018;65(1):125-37.

78. Cunha GM, Guzman G, Correa De Mello LL, Trein B, Spina L, Bussade , et al. Efficacy of a 2-month very low-calorie ketogenic diet (VLCKD) compared to a standard low-calorie diet in reducing visceral and liver fat accumulation in patients with obesity. Front Endocrinol. 2020;11:607.

79. Miller VJ, LaFountain RA, Barnhart E, Sapper TS, Short J, Arnold WD, et al. A Ketogenic diet combined with exercise alters mitochondrial function in human skeletal muscle while improving metabolic health. Am J Physiol Endocrinol Metab. 2020. https://doi.org/10.1152/ajpendo.00305.2020.

80. Bowie $A G$, Unterholzner L. Viral evasion and subversion of pattern-recognition receptor signalling. Nat Rev Immunol. 2008;8(12):911-22.

81. Franchi L, Nunez G. Immunology. Orchestrating inflammasomes. Science. 2012;337(6100):1299-300.

82. Swanson KV, Deng M, Ting JP. The NLRP3 inflammasome: molecular activation and regulation to therapeutics. Nat Rev Immunol. 2019;19(8):477-89.

83. Chen IY, Moriyama M, Chang MF, Ichinohe T. Severe acute respiratory syndrome coronavirus viroporin 3a activates the NLRP3 inflammasome. Front Microbiol. 2019:10:50

84. Horng T. Calcium signaling and mitochondrial destabilization in the triggering of the NLRP3 inflammasome. Trends Immunol. 2014;35(6):253-61.

85. Paoli A, Moro T, Bosco G, Bianco A, Grimaldi KA, Camporesi E, et al. Effects of n-3 polyunsaturated fatty acids (omega-3) supplementation on some cardiovascular risk factors with a ketogenic Mediterranean diet. Mar Drugs. 2015;13(2):996-1009.

86. Jeong EA, Jeon BT, Shin HJ, Kim N, Lee DH, Kim HJ, et al. Ketogenic dietinduced peroxisome proliferator-activated receptor-gamma activation decreases neuroinflammation in the mouse hippocampus after kainic acid-induced seizures. Exp Neurol. 2011;232(2):195-202.

87. Huang $X$, Xiu H, Zhang S, Zhang G. The role of macrophages in the pathogenesis of ALI/ARDS. Mediat Inflamm. 2018;2018:1264913.

88. Kaufmann SH. gamma/delta and other unconventional T lymphocytes: what do they see and what do they do? Proc Natl Acad Sci USA. 1996:93(6):2272-9.

89. Goldberg EL, Molony RD, Kudo E, Sidorov S, Kong Y, Dixit VD, et al. Ketogenic diet activates protective gammadelta $T$ cell responses against influenza virus infection. Sci Immunol. 2019:4(41):eaav2026.

90. Li H, Xiang Z, Feng T, Li J, Liu Y, Fan Y, et al. Human Vgamma9Vdelta2-T cells efficiently kill influenza virus-infected lung alveolar epithelial cells. Cell Mol Immunol. 2013;10(2):159-64.

91. Kohlgruber AC, Gal-Oz ST, LaMarche NM, Shimazaki M, Duquette D, Koay HF, et al. gammadelta T cells producing interleukin-17A regulate adipose regulatory $T$ cell homeostasis and thermogenesis. Nat Immunol. 2018;19(5):464-74.

\section{Publisher's Note}

Springer Nature remains neutral with regard to jurisdictional claims in published maps and institutional affiliations.
Ready to submit your research? Choose BMC and benefit from:

- fast, convenient online submission

- thorough peer review by experienced researchers in your field

- rapid publication on acceptance

- support for research data, including large and complex data types

- gold Open Access which fosters wider collaboration and increased citations

- maximum visibility for your research: over 100M website views per year

At BMC, research is always in progress.

Learn more biomedcentral.com/submissions 